\title{
Martin Ademmer* and Jens Boysen-Hogrefe The Impact of Forecast Errors on Fiscal Planning and Debt Accumulation
}

https://doi.org/10.1515/jbnst-2020-0054

Received October 18, 2020; accepted January 22, 2022

\begin{abstract}
We investigate the impact of errors in medium run tax revenue forecasts on the final budget balance. Our analysis is based on fiscal data for the entirety of German states and takes advantage of revenue forecasts and respective errors that can be considered as exogenously given in the budgeting process. We find that forecast errors at various forecast horizons translate considerably into the final budget balance, indicating that expenditure plans get only marginally adjusted when revenue forecasts get revised. Consequently, errors in tax revenue forecasts may considerably affect the accumulation of public debt. Our calculations suggest that a significant share of total debt of German states results from forecasts that were too optimistic.
\end{abstract}

Keywords: fiscal policy, fiscal planning, medium run forecasting, budget balance, public debt

JEL Classification: E62, H61, H68

\section{Introduction}

Continuous public deficits and rising debt-GDP ratios in many countries around the world demonstrate the need to better understand the determinants of budgetary outcomes. Most countries have adopted some form of multi-year fiscal planning to reduce the emphasis on short-run developments and to better account for fiscal challenges in the medium run (Auerbach 2006; Vlaicu et al. 2014). A key input for the fiscal planning process is forecasts of tax revenues, usually up to five years ahead. Based on the forecasted revenues, the government

Jens Boysen-Hogrefe represents the Kiel Institute for the World Economy in the 'Arbeitskreis Steuerschätzungen' (AKS).

*Corresponding author: Martin Ademmer, Kiel Institute for the World Economy, Kiellinie 66, 24105 Kiel, Germany, E-mail: martin.ademmer@ifw-kiel.de. https://orcid.org/0000-0002-7452-1293 Jens Boysen-Hogrefe, Kiel Institute for the World Economy, Kiellinie 66, 24105 Kiel, Germany, E-mail: jens.hogrefe@ifw-kiel.de

Ә Open Access. @ 2022 Martin Ademmer and Jens Boysen-Hogrefe, published by De Gruyter. (c) BY This work is licensed under the Creative Commons Attribution 4.0 International License. 
makes plans about expenditures in the coming years. It is well known, however, that GDP and tax revenue forecasts are often subject to substantial revisions (Beetsma et al. 2009; Cimadomo 2016), and typically, the revisions increase with the length of the forecast horizon. This leads to the question to what extent the government's expenditure plans get adjusted when tax revenue forecasts get revised or, in other words, to what extent errors in the tax revenue forecasts translate into the final budget balance. It also raises the question at which forecast horizon the revenue forecast errors have the most significant impact on the final budget balance of a given year. The aim of this paper is to empirically analyze both of these questions.

There are several difficulties when investigating the impact of revenue forecast errors on the budget balance in order to gain insight into the process of fiscal planning. Revenue forecasts can be politically influenced if policymakers seek for a justification of higher expenditures or want to signal a more prosperous stance of the economy (Jochimsen and Lehmann 2017; Pina and Venes 2011). ${ }^{1}$ Since the politically uninfluenced forecast is unknown in this case, such political considerations might lead to an errors-in-variables problem and to biased estimates in our empirical assessment. Furthermore, the link between revenue forecast errors and budgetary outcomes might be mismeasured, if fiscal policymakers actively react to the revenue forecasts by changing tax rates. For instance, lower taxes in reaction to a high revenue forecast affect the final revenues and, thus, the forecast error while possibly leaving the budget balance unchanged. ${ }^{2}$ This would result in underestimating the true impact of the forecast errors. Similarly, extraordinary public spending in response to business cycle fluctuations could also affect final revenues and the forecast error due to possible multiplier effects.

For these reasons, we make use of a unique data set of real-time revenue forecasts for the entirety of German states ('Länder') to analyze the relevance of medium run forecast errors. This set of revenue forecasts is not produced by the government but by an independent fiscal institution, namely the Working Party on Tax Revenue Estimates ('Arbeitskreis Steuerschätzungen', AKS). Since 1955, the AKS serves as an official advisory council for the German Federal Ministry of Finance and includes, inter alia, external experts from different research institutes, the staff of the German council of economic experts and the German Central Bank. ${ }^{3}$ The AKS provides forecasts for the overall tax revenues in Germany and a

1 See Heinemann (2006) for evidence regarding biased fiscal forecasts at the federal level in Germany. Moreover, Lehmann and Wollmershäuser (2020) show that business cycle projections made by the German federal government exhibit political biases at least in some periods.

2 Note that fiscal forecasts are usually made under a no-policy-change assumption (Leal et al. (2008)).

3 See Büttner and Kauder (2015) for a discussion of the independence of the AKS. 
breakdown into tax revenues of the Federal Government, the entirety of German states, and the entirety of German municipalities. Forecasts for individual German states are not publicly available (see Section 2.1).

Using the AKS forecasts and focusing on the entirety of German states has several advantages for our analysis. First, apart from the real estate transfer tax introduced in 2006 the German states have no tax sovereignty, which prevents any significant tax changes induced by relatively high or low revenue forecasts. Second, expenditures of German states are not driven by business cycle fluctuations, in contrast to expenditures of the German federal government. This is because cyclical fluctuations affect public expenditures mainly due to changes in unemployment, ${ }^{4}$ and unemployment benefits are provided at the federal level. The states are also only marginally engaged in active fiscal policy in response to the cycle. Thus, business cycle fluctuations mainly affect the budget balance via variations in tax revenues. Third, and most importantly, the states have very little power to politically influence the AKS forecasts. There is some evidence that budget balances of German states might be affected by political orientations and institutions in German States (Jochimsen and Nuscheler 2012) and even the socio-economic background of political leaders there (Hayo and Neumeier 2014). However, as long as the relevant decision makers for the fiscal plans of the states have no significant influence on the AKS forecasts (and thus on the relevant right hand side variables in our regression model) such possible political economy effects do not introduce a bias in our estimation and are therefore of minor relevance for our analysis. ${ }^{5}$

We therefore argue that the forecasts and forecast errors are largely exogenous to policy makers at the state level, which offers a relatively clean way to identify the impact of revenue forecast errors on the budgeting process. Furthermore, due to similar regulations and budgetary frameworks the results of this analysis might as well apply not only to the fiscal planning of the German federal government but also to the fiscal planning of other countries in the European Union.

Our results show that revenue forecast errors translate to a large extent into the final budget balance. In particular, we find that forecast errors at various forecast horizons matter. Not only the one-year ahead forecast errors but also the two-year and three-year ahead forecast errors significantly affect the budgetary outcome. The average revenue forecast error across all forecast horizons ultimately enters with around four-fifth in the budget balance. Our results therefore indicate that expenditure plans for future years adjust only to a minor degree to revisions in tax

4 See, for instance, OECD (2014).

5 Furthermore, one could also argue that potential political economy effects at the individual state level might balance out when considering the entirety of German states. 
revenue forecasts. Consequently, errors in medium run forecasts can have a sizeable impact on the accumulation of public debt. Some back-of-the-envelope calculations suggest that a significant share of total debt of German states results from revenue forecasts that were too optimistic.

So far, the empirical evidence on the consequences of revenue forecast errors has been rather limited. One exception is Chatagny and Soguel (2012) who use panel data from Swiss cantons between 1980 and 2002 to analyze the impact of tax revenue budgeting errors on fiscal deficits. They find that underestimating tax revenues significantly reduces fiscal deficits. Taking a broader perspective on the drivers of ex post budgetary outcomes, Beetsma et al. (2009) decompose the budget balance of countries of the European Union into planned and error components and explore their economic and political determinants. They inter alia report that planned positive budgetary adjustments are more than offset by negative implementation errors, thereby producing negative actual adjustments. Beetsma et al. (2013) perform a similar analysis for the Netherlands. Moreover, Cimadomo (2012) emphasizes the role of forecast errors in the cyclical component of GDP for the stance of fiscal policy, estimating fiscal reaction functions based on real-time data of OECD countries.

We contribute to this literature in several ways. First, the nature of our forecast data provides a rare opportunity to abstract from the influence of a broad set of political factors, which are often hard to measure and to control for. We are therefore able to study the impact of revenue forecasts and respective errors that can be considered as exogenously given in the budgeting process. Second, in contrast to other studies we explicitly take into account forecast errors at five different horizons. This allows us to shed light on the most relevant horizons and to better understand the process of fiscal planning in general. Beyond that, the results of our paper may add to the ongoing discussion of fiscal rules by pointing to the need of a framework that prevents biased forecasts to destabilize public debt. $^{6}$

Our paper also contributes to the literature on macroeconomic consequences of over-optimism (see Beaudry and Willems (2018) and references therein). Based on IMF data for a panel of 189 countries, Beaudry and Willems (2018) show that overly-optimistic growth forecasts make later recessions and financial crises more likely and argue that this mechanism may run through higher (public and private) debt accumulation. Our findings corroborate their argument by having a more detailed look at the effects on public finances in an advanced economy.

6 See European Commission (2018) for a review of fiscal surveillance and fiscal rules in the European Union. 
The structure of the paper is as follows. We first present the data set and the empirical framework (Section 2). We then discuss our main results regarding the impact of forecast errors on the budget balance, run alternative specifications to check for the robustness of our results, and have a closer look at different horizons as well as potential asymmetric effects (Section 3). Based on the previous empirical estimates we finally explore the consequences of forecast errors on the debt-GDP ratio (Section 4). Section 5 concludes.

\section{Empirical Framework}

\subsection{Data}

For our analysis, we use the AKS medium run tax revenue forecasts for the entirety of German states. We obtain these data from press releases of the German Federal Ministry of Finance that were published after each AKS meeting. The AKS medium run forecasts comprise estimates for the current year and the following four years. While the AKS as an independent institution exists since 1955, the complete set of estimates for all five horizons is only available from 1972 onwards. Our sample therefore starts in 1976. In recent years, the AKS conducts two forecasting rounds each year, one in spring and one in autumn. We take the spring forecasts from each year because during the period from 1986 to 2011 there were no medium run projections in autumn. The spring forecasts are usually published in May. In the years before 1986, however, the release of the first forecast in each year varied between February (1972, 1978) and August (1973, 1975-1977). Nevertheless, our setup offers the best possible comparability of the forecasts over time and horizons. All other (ex post) fiscal data are obtained from the German Federal Statistical Office. ${ }^{7}$

We focus on the entirety of German states for the simple reason that even though the AKS also divides its forecast of total tax revenues into the tax revenues of individual states, these calculations are destined exclusively for the state governments and not made publicly available. ${ }^{8}$ The subsequent own fiscal forecasts of the individual states are publicly available. However, since the states are not bound to the input of the AKS their forecasts are prone to political considerations (Bischoff and Gohout 2010) and therefore not useful for our analysis. Due to the reunification the overall number of German states increased from 11 to 16 in October 1990 while the forecasts made in the late ' 80 s for the early

7 Detailed data sources can be found in Appendix A.3.

8 See Federal Ministry of Finance (2019) for details. 
' 90 s refer to the former 11 states only. For this reason, we stick to the entirety of 11 states until the year 1994. This is possible, since the AKS separately reported forecasts for the old 11 as well as the five new states in the first years after the reunification. From 1995 onwards we then include all 16 states.

Figure 1 shows the revenue forecast errors of the AKS at different horizons, expressed in relation to nominal GDP. The forecast errors are defined as the difference between the ex post tax revenues in a given period $t$ and the real-time forecasts for the tax revenues in $t$ made in period $t-i$. As expected, the forecast errors are usually smaller the shorter the forecast horizon. The mean absolute error decreases from around 0.8 for the four-year ahead forecast to nearly 0.1 for the current year forecast (Table 1). The mean error for the current year forecast and the one-year ahead forecast is positive but small, which means that at these horizons revenues are on average slightly underestimated. At longer horizons (two-, threeand four-year ahead forecast) the mean error is considerably negative, which means that on average revenues are overestimated. We will get back to the notable upward-bias of the medium run forecasts in Section $4 .^{9}$ Chronologically, we

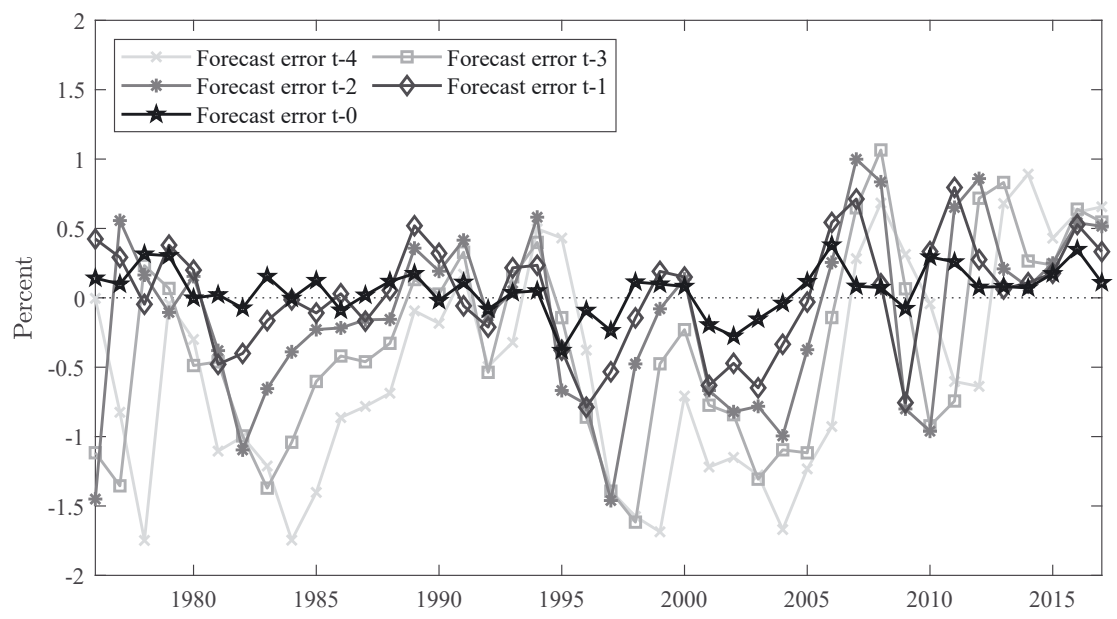

Figure 1: Revenue forecast errors 1976-2017. Revenue forecast errors in relation to nominal GDP at different forecast horizons.

9 Note that a bias in (medium run) forecasts is not unusual and also found in forecasts of other independent institutions like the IMF (IEO 2014). A bias in the medium run tax revenue forecasts for the general German government is documented in Breuer (2015). Based on a sample of OECD countries Büttner and Kauder (2010), however, find that the precision of revenue forecasts increases with the independence of forecasts from possible government manipulations. 
Table 1: Descriptive statistics of key variables.

\begin{tabular}{lrrrrrr}
\hline & Mean & MAE & RMSE & Std & Min & Max \\
\hline Forecast error $t$-4 & -0.52 & 0.78 & 0.93 & 0.78 & -1.75 & 0.89 \\
Forecast error $t$-3 & -0.34 & 0.65 & 0.77 & 0.70 & -1.62 & 1.07 \\
Forecast error $t$ - 2 & -0.14 & 0.51 & 0.63 & 0.62 & -1.46 & 1.00 \\
Forecast error $t$-1 & 0.01 & 0.32 & 0.39 & 0.39 & -0.79 & 0.80 \\
Forecast error $t$-0 & 0.06 & 0.14 & 0.17 & 0.16 & -0.38 & 0.38 \\
Cross-horizon mean forecast error & -0.19 & 0.39 & 0.46 & 0.43 & -1.00 & 0.55 \\
\hline Primary balance-GDP ratio & 0.05 & & & 0.48 & -0.80 & 0.97 \\
Expenditure-GDP ratio & 12.37 & & & 0.66 & 10.93 & 13.61 \\
Output gap & -0.05 & & & 1.74 & -4.07 & 4.05 \\
Debt-GDP ratio & 15.48 & & & 4.61 & 7.02 & 23.38 \\
\hline
\end{tabular}

Sample 1976-2017. Revenue forecast errors in relation to nominal GDP at different forecast horizons and on average across all horizons; MAE: Mean absolute error; RMSE: Root mean squared error; Std: Standard deviation.

observe periods in which tax revenues were overestimated especially around the years 1981-1985 and 1997-2005. By contrast, tax revenues in the late '80s and early ' 90 s as well as in the more recent years from 2011 onwards were underestimated.

\subsection{The Baseline Regression Model}

We denote the tax revenue forecast made in year $t-i$ for the year $t$, expressed in relation to nominal GDP $Y_{t}$, by $r_{t \mid t-i}$. Accordingly, $f_{t \mid t-i}=\left(r_{t}-r_{t \mid t-i}\right)$ denotes the corresponding forecast error. We are interested in the effect of the forecast error $f_{t \mid t-i}$ at different forecast horizons $t-i, i=0,1, \ldots, 4$, on the final primary balance-GDP ratio $p_{t}$. The primary balance is defined as overall revenues, mostly consisting of tax revenues, less expenditures (excluding interest payments). Our baseline specification takes the form:

$$
p_{t}=\alpha+\sum_{i=0}^{4} \beta_{i} f_{t \mid t-i}+\gamma \mathbf{x}_{t}+\delta \mathbf{d}_{t}+u_{t}
$$

The vector $\mathbf{x}_{t}$ comprises additional explanatory variables. We consider an estimate of the output gap $\left(g_{t}\right)$ based on the Hodrick-Prescott filtered real GDP series and the debt-GDP ratio of the previous year $\left(b_{t-1}\right) \cdot{ }^{10}$ Both are typical

10 We take the Hodrick-Prescott filter-based output gap series for Germany from the European Commission's AMECO database. Our results remain almost unchanged when using an estimate of the output gap based on the European Commission's production function approach instead of the Hodrick-Prescott filter. 
explanatory variables in the literature on fiscal reaction functions (Golinelli and Momigliano 2009). The vector $\mathbf{d}_{t}$ comprises a set of dummy variables that have a value of one in the years 1992, 1993, and 1994, respectively. We include these dummy variables for the reason that from 1992 to 1994 the forecast errors still refer to the 11 West German states only as (medium run) forecast errors for the five new states are not available yet. GDP and budget balance data, however, refer to all 16 states of reunified Germany.

In addition to our baseline specification with the primary balance-GDP ratio $p_{t}$ as dependent variable we also consider regressions with the expenditure-GDP ratio $e_{t}$ as dependent variable (see Appendix A.2). Generally, a regression with expenditures on the left hand side is prone to simultaneous shifts in expenditures and revenues, for instance due to a change in the size of the government sector or federal structures. Such a regression is therefore more likely to be affected by omitted variables or structural instabilities than our baseline regression model with the primary budget balance on the left hand side.

When estimating (1) there might be problems of serial correlation and endogeneity. Serial correlation of the errors is a large issue, as signaled by a DurbinWatson statistic of around 0.8. To address it, we follow Plödt and Reicher (2015) and model $u_{t}$ as an autoregressive process. More specifically, $u_{t}$ is assumed to follow an $\operatorname{AR}(2)$ process with persistence coefficients $\rho_{1}$ and $\rho_{2}$, i.e.

$$
u_{t}=\rho_{1} u_{t-1}+\rho_{2} u_{t-2}+\epsilon_{t}
$$

where $\varepsilon_{t}$ is independent over time. The choice of $\operatorname{AR}(2)$ errors is motivated by the fact that we still find evidence for serial correlation when employing a specification with first-order AR errors only.$^{11} \mathrm{~A}$ problem of endogeneity would arise when the budget balance reacts to the output gap and the output gap is affected in turn by fiscal policy. In our context, however, this simultaneity is likely to be minor since the individual states are only marginally engaged in active fiscal policy. We therefore refrain from an instrumental variable approach. In Section 3.2 we perform several sensitivity analyses with respect to our chosen baseline specification.

\section{Forecast Errors and Fiscal Planning}

\subsection{Results for Different Horizons}

The estimation results for our baseline model are presented in Table 2 (specification A1). Our main finding is that not only the one-year ahead forecast errors but

11 The choice of this specification is also supported by different information criteria (see Table 2). 
Table 2: Baseline results and alternative specifications.

\begin{tabular}{|c|c|c|c|c|c|c|}
\hline & $\begin{array}{r}(\mathrm{A} 1) \\
p_{t} \\
1976-2017\end{array}$ & $\begin{array}{r}(\mathrm{A} 2) \\
p_{t} \\
1976-2017\end{array}$ & $\begin{array}{r}(\mathrm{A} 3) \\
p_{t} \\
1976-2008\end{array}$ & $\begin{array}{r}(\mathrm{A} 4) \\
p_{t} \\
1976-2017\end{array}$ & $\begin{array}{r}\text { (A5) } \\
p_{t} \\
1976-2017\end{array}$ & $\begin{array}{r}(\mathrm{A} 6) \\
p_{t} \\
1976-2008\end{array}$ \\
\hline$\overline{f_{t \mid t-0}}$ & $\begin{array}{l}-0.007 \\
(0.164)\end{array}$ & $\begin{array}{r}0.088 \\
(0.224)\end{array}$ & $\begin{array}{r}0.121 \\
(0.234)\end{array}$ & $\begin{array}{l}-0.266 \\
(0.187)\end{array}$ & $\begin{array}{l}-0.172 \\
(0.253)\end{array}$ & $\begin{array}{l}-0.139 \\
(0.264)\end{array}$ \\
\hline$f_{t \mid t-1}$ & $\begin{array}{c}0.291^{b} \\
(0.120)\end{array}$ & $\begin{array}{r}0.355^{\mathrm{a}} \\
(0.117)\end{array}$ & $\begin{array}{r}0.396^{\mathrm{a}} \\
(0.114)\end{array}$ & $\begin{array}{r}0.112 \\
(0.107)\end{array}$ & $\begin{array}{r}0.117 \\
(0.115)\end{array}$ & $\begin{array}{r}0.180 \\
(0.141)\end{array}$ \\
\hline$f_{t \mid t-2}$ & $\begin{array}{c}0.265^{\mathrm{a}} \\
(0.060)\end{array}$ & $\begin{array}{c}0.307^{\mathrm{a}} \\
(0.063)\end{array}$ & $\begin{array}{r}0.278^{\mathrm{a}} \\
(0.091)\end{array}$ & $\begin{array}{r}0.415^{\mathrm{a}} \\
(0.087)\end{array}$ & $\begin{array}{c}0.437^{\mathrm{a}} \\
(0.075)\end{array}$ & $\begin{array}{c}0.404^{\mathrm{a}} \\
(0.084)\end{array}$ \\
\hline$f_{t \mid t-3}$ & $\begin{array}{l}0.124^{b} \\
(0.052)\end{array}$ & $\begin{array}{c}0.134^{b} \\
(0.063)\end{array}$ & $\begin{array}{r}0.116^{c} \\
(0.059)\end{array}$ & $\begin{array}{c}0.168^{\mathrm{a}} \\
(0.058)\end{array}$ & $\begin{array}{c}0.187^{\mathrm{b}} \\
(0.075)\end{array}$ & $\begin{array}{r}0.166^{c} \\
(0.079)\end{array}$ \\
\hline$f_{t \mid t-4}$ & $\begin{array}{r}0.083 \\
(0.057)\end{array}$ & $\begin{array}{r}0.036 \\
(0.064)\end{array}$ & $\begin{array}{r}0.058 \\
(0.073)\end{array}$ & $\begin{array}{r}0.101 \\
(0.073)\end{array}$ & $\begin{array}{r}0.065 \\
(0.071)\end{array}$ & $\begin{array}{r}0.118 \\
(0.088)\end{array}$ \\
\hline$g_{t}$ & $\begin{array}{l}-0.030 \\
(0.026)\end{array}$ & $\begin{array}{r}-0.057^{b} \\
(0.023)\end{array}$ & $\begin{array}{l}-0.023 \\
(0.047)\end{array}$ & $\begin{array}{r}-0.043^{c} \\
(0.023)\end{array}$ & $\begin{array}{r}-0.047^{b} \\
(0.020)\end{array}$ & $\begin{array}{l}-0.029 \\
(0.055)\end{array}$ \\
\hline$g_{t-1}$ & & & & $\begin{array}{r}-0.081^{b} \\
(0.030)\end{array}$ & $\begin{array}{r}-0.088^{b} \\
(0.041)\end{array}$ & $\begin{array}{r}-0.113^{b} \\
(0.049)\end{array}$ \\
\hline$b_{t-1}$ & $\begin{array}{r}0.035 \\
(0.026)\end{array}$ & $\begin{array}{r}0.021 \\
(0.030)\end{array}$ & $\begin{array}{r}0.061 \\
(0.048)\end{array}$ & $\begin{array}{r}0.024 \\
(0.018)\end{array}$ & $\begin{array}{r}0.015 \\
(0.022)\end{array}$ & $\begin{array}{c}0.047^{b} \\
(0.021)\end{array}$ \\
\hline$\alpha$ & $\begin{array}{l}-0.353 \\
(0.457)\end{array}$ & $\begin{array}{l}-0.126 \\
(0.523)\end{array}$ & $\begin{array}{l}-0.716 \\
(0.742)\end{array}$ & $\begin{array}{l}-0.143 \\
(0.317)\end{array}$ & $\begin{array}{r}0.005 \\
(0.368)\end{array}$ & $\begin{array}{l}-0.424 \\
(0.341)\end{array}$ \\
\hline$\rho_{1}$ & $\begin{array}{l}1.143^{\mathrm{a}} \\
(0.201)\end{array}$ & $\begin{array}{r}0.704^{a} \\
(0.088)\end{array}$ & $\begin{array}{l}1.190^{\mathrm{a}} \\
(0.278)\end{array}$ & $\begin{array}{l}1.057^{\mathrm{a}} \\
(0.274)\end{array}$ & $\begin{array}{c}0.666^{\mathrm{a}} \\
(0.093)\end{array}$ & $\begin{array}{l}1.043^{\mathrm{a}} \\
(0.276)\end{array}$ \\
\hline$\rho_{2}$ & $\begin{array}{c}-0.494^{b} \\
(0.231)\end{array}$ & & $\begin{array}{l}-0.484 \\
(0.333)\end{array}$ & $\begin{array}{r}-0.490^{c} \\
(0.247)\end{array}$ & & $\begin{array}{r}-0.474^{\mathrm{c}} \\
(0.263)\end{array}$ \\
\hline Obs. & 42 & 42 & 33 & 42 & 42 & 33 \\
\hline Adj. $R^{2}$ & 0.867 & 0.846 & 0.856 & 0.886 & 0.868 & 0.878 \\
\hline AIC & -0.404 & -0.298 & & -0.540 & -0.432 & \\
\hline SIC & 0.145 & 0.204 & & 0.051 & 0.111 & \\
\hline
\end{tabular}

Dependent variable: Primary balance-GDP ratio. Robust standard errors are given in parentheses. See Eqs. (1) and (2), and main text for further details. ${ }^{\mathrm{a}} /{ }^{\mathrm{b}} /{ }^{\mathrm{c}}$ indicates statistical significance at the $1 \% / 5 \% / 10 \%$ level; AIC: Akaike information criterion; SIC: Schwarz information criterion. Bold values are the same as in other tables. pt is also defined in text alongside all other variables listed in first column.

also the two-year and three-year ahead forecast errors have an economically and statistically significant effect on the primary balance-GDP ratio $p_{t}$. The strongest impact exhibit the forecast errors made in period $t-1$ and $t-2$. A revenue forecast error of 1 percentage point in each of these periods leads to change of almost 0.3 percentage points in the actual primary balance-GDP ratio. ${ }^{12} \mathrm{~A}$ revenue forecast

12 Note that the standard deviation of the primary balance-GDP ratio over the sample period is 0.5 percentage points. A change of 0.3 percentage points therefore corresponds to more than half a standard deviation. 
error of 1 percentage point in period $t-3$ leads to a change of around 0.1 percentage points. The four-year ahead forecast error $f_{t \mid t-4}$ also has a small effect on the budget balance though the estimated coefficient is not statistically significant at common significance levels. In contrast, the estimated coefficient for $f_{t \mid t-0}$ is nearly zero, which means that the spring forecast for the current year is almost irrelevant for the budgetary outcome.

We include the output gap as a measure for the business cycle to avoid overly persistent residuals and a possible omitted variable bias. The corresponding coefficient is estimated close to zero. The estimated debt coefficient is slightly positive but also not statistically distinguishable from zero. We thus find no strong evidence for consolidation policies of German states in response to past debt. The persistence coefficients are both sizeable and statistically significant, showing that serial correlation of the residuals is indeed an issue in the regression model given by Eq. (1).

\subsection{Sensitivity Analyses}

We perform several robustness checks to test the sensitivity of our baseline results to alternative model specifications. First, we model the residuals $u_{t}$ as an AR(1) instead of an $\mathrm{AR}(2)$ process (specification A2). We find that the specification with $\mathrm{AR}(1)$ errors delivers results that are very close to our baseline specification. Second, we check the temporal stability of our results. To do so, we compare our baseline results with the results of a shorter pre-crisis sample ranging from 1976 to 2008 (A3). The choice of this sample is also motivated by the fact that the German debt brake was introduced on the federal level after the financial crisis and some of the Länder have also introduced a debt brake in the following years. ${ }^{13}$ We find that the estimated coefficients based on the shorter pre-crisis sample are broadly similar to the baseline estimates, indicating that the impact of the forecast errors has not changed significantly over time and that our baseline results are not noticeably driven by extraordinary events subsequent to the financial crisis. Third, we add both, the contemporaneous output gap as well as the output gap of the previous year as explanatory variables (A4). In this case, we find an even stronger impact of the two-year ahead forecast error $f_{t \mid t-2}$ and a smaller and statistically insignificant impact of $f_{t \mid t-1}$. The results of this specification are again only marginally affected when using AR(1) errors or a shorter pre-crisis sample (specification A5 and A6, respectively).

13 However, the debt brake only became mandatory for all Länder in the year 2020. Since this period is outside of our sample, our study does not allow for a closer investigation of the potential influence of the debt brake on forecast errors and fiscal planning. 
In Appendix A.1, we present a further set of robustness checks, in particular with regard to the handling of serial correlation, potential issues when dividing the dependent and the independent variables by a common denominator, and the use of a cyclically-adjusted primary balance variable. Overall, we conclude from all of these sensitivity analyses that our main findings are remarkably robust across alternative specifications and samples.

\subsection{Cross-Horizon Mean Error and Asymmetric Reactions}

So far, our baseline specification has included all the individual forecast errors $f_{t \mid t-i}$ to investigate the importance of each forecast horizon $t-i$. In this subsection we consider instead the cross-horizon mean forecast error as explanatory variable. This allows us to quantify the impact of the average error across all forecast horizons concerning the tax revenues in a specific period $t$. Given our relatively small sample size, it also allows us to obtain a more parsimonious model. In particular, we calculate $f_{t \mid t-i}^{04}=\frac{1}{5} \sum_{i=0}^{4} f_{t \mid t-i}$ and estimate

$$
p_{t}=\alpha+\beta f_{t \mid t-i}^{04}+\gamma \mathbf{x}_{t}+\delta \mathbf{d}_{t}+u_{t} .
$$

The corresponding results are displayed in Table 3 (specification B1). The estimated coefficient for $f_{t \mid t-i}^{04}$ equals around 0.8 , with a value of one being within the one-standard error band. When considering the pre-crisis sample 1976-2008 (B2), we find an even higher point estimate of around 0.9. Moreover, adding both, the contemporaneous output gap as well as the output gap of the previous year as explanatory variables only marginally affects the results (B3).

These estimates show that the overwhelming part (around four-fifth) of the cross-horizon mean forecast error for a specific period ultimately translates into the final budget balance. They also suggest that revisions in revenue forecasts lead only to a minor degree to adjustments in the government's expenditure plans. To empirically support this argument, we additionally regress the expenditure-GDP ratio on the cross-horizon mean forecast error (see Appendix A.2). We indeed find that the reaction of expenditures to the mean forecast error is very small and not statistically distinguishable from zero. ${ }^{14}$

14 We consider these results to be in line with Chatagny and Soguel (2012). Based on a different model setup, they find that revenue forecast errors affect actual expenditures in a similar magnitude as actual revenues. This corroborates our finding that revenue forecast errors translate to a large extent into the budget balance and fits with our interpretation that expenditure plans are rarely adjusted according to revisions of tax revenues. 
Table 3: Cross-horizon mean error and asymmetric reactions.

\begin{tabular}{|c|c|c|c|c|c|}
\hline & $\begin{array}{r}(\mathrm{B} 1) \\
p_{t} \\
1976-2017\end{array}$ & $\begin{array}{r}(\mathrm{B} 2) \\
p_{t} \\
1976-2008\end{array}$ & $\begin{array}{r}(\mathrm{B} 3) \\
p_{t} \\
1976-2017\end{array}$ & $\begin{array}{r}(\mathrm{B} 4) \\
p_{t} \\
1976-2017\end{array}$ & $\begin{array}{r}(\mathrm{B} 5) \\
p_{t} \\
1976-2017\end{array}$ \\
\hline$f_{t \mid t-i}^{04}$ & $\begin{array}{l}0.809^{\mathrm{a}} \\
(0.201)\end{array}$ & $\begin{array}{l}0.933^{\mathrm{a}} \\
(0.196)\end{array}$ & $\begin{array}{l}0.830^{\mathrm{a}} \\
(0.212)\end{array}$ & & \\
\hline$f_{t \mid t-i}^{01}$ & & & & $\begin{array}{r}0.427 \\
(0.262)\end{array}$ & \\
\hline$f_{t \mid t-i}^{24}$ & & & & $\begin{array}{l}0.450^{\mathrm{a}} \\
(0.108)\end{array}$ & \\
\hline$f_{t \mid t-i}^{04 p o s}$ & & & & & $\begin{array}{c}0.787^{b} \\
(0.289)\end{array}$ \\
\hline$f_{t \mid t-i}^{04 n e g}$ & & & & & $\begin{array}{l}0.819^{\mathrm{a}} \\
(0.254)\end{array}$ \\
\hline$g_{t}$ & $\begin{array}{l}-0.010 \\
(0.020)\end{array}$ & $\begin{array}{l}-0.037 \\
(0.056)\end{array}$ & $\begin{array}{l}-0.018 \\
(0.029)\end{array}$ & $\begin{array}{l}-0.017 \\
(0.031)\end{array}$ & $\begin{array}{l}-0.009 \\
(0.021)\end{array}$ \\
\hline$g_{t-1}$ & & & $\begin{array}{l}-0.019 \\
(0.033)\end{array}$ & & \\
\hline$b_{t}-1$ & $\begin{array}{r}0.043 \\
(0.031)\end{array}$ & $\begin{array}{r}0.075 \\
(0.056)\end{array}$ & $\begin{array}{r}0.038 \\
(0.028)\end{array}$ & $\begin{array}{r}0.041 \\
(0.031)\end{array}$ & $\begin{array}{r}0.043 \\
(0.030)\end{array}$ \\
\hline$\alpha$ & $\begin{array}{l}-0.480 \\
(0.549)\end{array}$ & $\begin{array}{l}-0.863 \\
(0.871)\end{array}$ & $\begin{array}{l}-0.398 \\
(0.507)\end{array}$ & $\begin{array}{l}-0.447 \\
(0.551)\end{array}$ & $\begin{array}{l}-0.479 \\
(0.564)\end{array}$ \\
\hline$\rho_{1}$ & $\begin{array}{c}1.162^{\mathrm{a}} \\
(0.184)\end{array}$ & $\begin{array}{l}1.184^{\mathrm{a}} \\
(0.265)\end{array}$ & $\begin{array}{l}1.086^{\mathrm{a}} \\
(0.269)\end{array}$ & $\begin{array}{l}1.104^{\mathrm{a}} \\
(0.233)\end{array}$ & $\begin{array}{l}1.166^{\mathrm{a}} \\
(0.190)\end{array}$ \\
\hline$\rho_{2}$ & $\begin{array}{c}-0.489^{b} \\
(0.224)\end{array}$ & $\begin{array}{l}-0.499 \\
(0.307)\end{array}$ & $\begin{array}{l}-0.424 \\
(0.286)\end{array}$ & $\begin{array}{l}-0.433 \\
(0.278)\end{array}$ & $\begin{array}{r}-0.492^{b} \\
(0.234)\end{array}$ \\
\hline $\begin{array}{l}\text { Obs. } \\
\text { Adj. } R^{2}\end{array}$ & $\begin{array}{r}42 \\
0.857\end{array}$ & $\begin{array}{r}33 \\
0.847\end{array}$ & $\begin{array}{r}42 \\
0.855\end{array}$ & $\begin{array}{r}42 \\
0.854\end{array}$ & $\begin{array}{r}42 \\
0.853\end{array}$ \\
\hline
\end{tabular}

Dependent variable: Primary balance-GDP ratio. Robust standard errors are given in parentheses. See Eqs. (3) and (4) as well as main text for further details. ${ }^{\mathrm{a}} / \mathrm{b}^{\mathrm{c}}$ indicates statistical significance at the $1 \% / 5 \% /$ $10 \%$ level.

Next, we have a closer look at the budget impact of the average error over the medium run horizons $t-i, i=2,3,4$ versus the short-run horizons $t-i, i=0,1$. For this specification we calculate $f_{t \mid t-i}^{24}=\frac{1}{3} \sum_{i=2}^{4} f_{t \mid t-i}$ and $f_{t \mid t-i}^{01}=\frac{1}{2} \sum_{i=0}^{1} f_{t \mid t-i}$ and include both as explanatory variables in our model (specification B4). We find a strong effect of the medium run mean forecast error on the primary balance-GDP ratio, with an estimated coefficient for $f_{t \mid t-i}^{24}$ of almost 0.5. Moreover, we find a slightly lower coefficient for $f_{t \mid t-i}^{01}$, which is not statistically significant at common levels. This result again demonstrates the importance of the medium run forecasts for the final budgetary outcome. 
Finally, we explore potential asymmetric reactions of the primary balanceGDP ratio to forecast errors. To do so, we consider a model specification that allows for different reactions to positive and negative cross-horizon mean forecast errors. This specification takes the form:

$$
p_{t}=\alpha+\beta_{1} f_{t \mid t-i}^{04 p o s}+\beta_{2} f_{t \mid t-i}^{04 n e g}+\gamma \mathbf{x}_{t}+\delta \mathbf{d}_{t}+u_{t} .
$$

Our estimation results do not point to notable asymmetric reactions (B5). The difference between the reaction to positive and negative forecast errors is very minor and not statistically significant. These results suggest that in the long term forecast errors contribute to an increase in debt levels, if forecasts are overall too optimistic. On the other hand, forecast errors that go in both directions may cancel each other out. Hence, the results of this specification underline the importance of unbiased forecasts.

\section{Forecast Errors and Debt Accumulation}

The regression results from the previous section show that not only the errors in the one-year ahead forecast but also in the medium run forecasts matter for the final budget balance. Given the (upward) bias of the medium run forecasts documented in Section 2.1, we now perform some back-of-the-envelope calculations to derive the impact of the forecast errors since the beginning of our sample period on the accumulation of debt. This exercise is meant to illustrate the link between forecast errors and the sustainability of public finances.

We assume that the debt stock $B_{t}$ follows the law of motion

$$
B_{t}=B_{t-1}+i_{t} B_{t-1}-P_{t},
$$

where $P_{t}$ denotes the primary balance and $i_{t}$ denotes the implicit interest rate given by the interest expenditures in period $t$ divided by the end-of-period debt in the previous period $t-1 .^{15} 16$ We then calculate the effect of the forecast errors on the primary balance using our baseline estimates from specification A1:

$$
P_{t}^{f}=\left(\sum_{i=0}^{4} \widehat{\beta}_{i} f_{t \mid t-i}\right) Y_{t}
$$

15 Note that the budget balance rather corresponds to net debt as a stock and that gross debt can be affected by stock-flow adjustments. To simplify matters, we assume stock-flow adjustments to be zero.

16 The implicit interest rate assumes that new debt is issued to the same conditions as they apply for the average debt stock. For simplicity, in this exercise we disregard any short-run fluctuations of interest rates and possible feedback from the debt level to risk premia. 
Accordingly, the hypothetical primary balance without forecast errors is given by

$$
P_{t}^{*}=P_{t}-P_{t}^{f},
$$

and the hypothetical debt stock without forecast errors is given by

$$
B_{t}^{\star}=B_{t-1}^{\star}+i_{t} B_{t-1}^{\star}-P_{t}^{\star} .
$$

Finally, from the difference between (5) and (8) we obtain the impact of the errors on the accumulation of debt:

$$
B_{t}^{f}=B_{t}-B_{t}^{*} .
$$

In line with the estimated debt coefficient in specification A1, we do not consider a systematic response of German states to past debt levels. A significantly positive debt response would mitigate the impact of biased medium run forecasts on the accumulation of debt.

Figure 2 shows on the left hand side the calculated impact of the revenue forecast errors on the primary budget balance and debt over time. Particularly striking is the continuous negative effect on the primary budget balance from the mid '90s until the year 2005, which led to a strong increase in debt. From 2011 onwards, the forecast error effect on the primary budget balance is positive. Because of interest payments, however, the resulting error-based debt stock declines only slowly. The debt-GDP ratio of German states due to forecast errors as well as the share of debt due to forecast errors in total debt is plotted on the right hand side of Figure 2. Our calculations show that roughly 40 percent of total debt of German states results from forecasts in our sample period that overestimated the actual revenues.
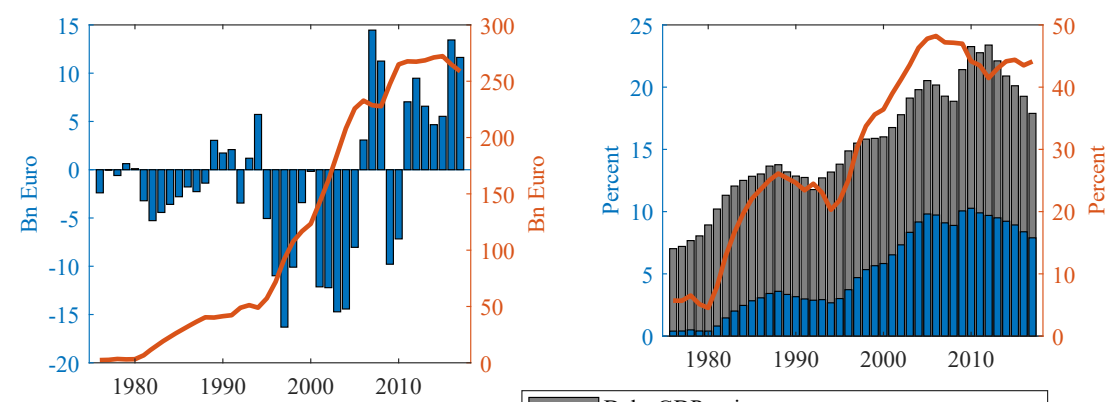

Forecast error effect on primary balance Forecast error effect on debt (right axis)

Debt-GDP ratio

Debt-GDP ratio due to forecast errors Share of debt due to forecast errors (right axis)

Figure 2: Forecast errors and debt accumulation. Left figure: Impact of revenue forecast errors on the primary budget balance and debt over time. Right figure: Debt-GDP ratio of German states due to forecast errors and share of debt due to forecast errors in total debt. 


\section{Conclusions}

Based on a data set for German states, our analysis has shown that even errors in several-year ahead revenue forecasts significantly affect the final budget balance. This suggests that expenditures get often binding once they are planned and therefore get only marginally adjusted over the planning period. Revenue forecasts that are overly optimistic may therefore lead to an accumulation of additional debt.

Our findings underline the importance of accurate and unbiased forecasts for fiscal planning and emphasize the relevance of the medium run forecast horizon in this regard. Since independent institutions are more likely to provide less biased forecasts, our findings are supportive to the EU commission's request that member states set up independent business cycle and budgetary forecasts for fiscal planning. Our findings also point to the need of further research to improve the accuracy and unbiasedness of forecasts of the economic development in the medium run. The unbiasedness of medium run forecasts is especially important since a very high degree of flexibility in fiscal planning, i.e. reacting promptly to forecast revisions and forecast errors, as a way to deal with biased forecasts is not without costs. This is because the consistency of fiscal plans is likely to serve as a stabilizing factor that reduces fluctuations in the business cycle. Sudden and extensive reactions to emerging forecast errors, on the other hand, might reduce these benefits of multi-year fiscal planning.

Finally, it should be noted that our analysis is based on a sample period in which the German debt brake became mandatory for the federal government but not for the individual Länder, and only some Länder introduced a debt brake before the end of our sample. Future work might therefore have a closer look at potential differences after the mandatory introduction of the debt brake for the Länder in the year 2020.

\section{A Appendix}

\section{A.1 Further Robustness Checks}

In this appendix, we present a further set of robustness checks of our baseline results (Table A1). We first explore potential differences when simply including a lagged dependent variable on the right hand side of Eq. (1) to deal with serial correlation (specification A7). We find that the specification with a lagged dependent variable also indicates a strong impact of the one-year ahead and twoyears ahead forecast errors. In contrast to our baseline specification, we do not find 
Table A1: Baseline model - further robustness checks.

\begin{tabular}{|c|c|c|c|c|c|c|}
\hline & $\begin{array}{r}(\mathrm{A} 7) \\
p_{t} \\
1976-2017\end{array}$ & $\begin{array}{r}(\text { A8) } \\
p_{t} \\
1976-2017\end{array}$ & $\begin{array}{r}(\mathrm{A} 9) \\
p_{t} \\
1976-2017\end{array}$ & $\begin{array}{r}(\mathrm{A} 10) \\
p_{t} \\
1976-2017 \\
\text { [d92 only] }\end{array}$ & $\begin{array}{r}(\mathrm{A} 11) \\
p_{t} \\
1976-2017 \\
\text { [bn Euro] }\end{array}$ & $\begin{array}{r}\text { (A12) } \\
\text { capt }_{t} \\
1976-2017\end{array}$ \\
\hline$f_{t \mid t-0}$ & $\begin{array}{l}-0.208 \\
(0.221)\end{array}$ & $\begin{array}{l}-0.156 \\
(0.241)\end{array}$ & $\begin{array}{l}-0.251 \\
(0.248)\end{array}$ & $\begin{array}{l}-0.143 \\
(0.147)\end{array}$ & $\begin{array}{l}-0.043 \\
(0.208)\end{array}$ & $\begin{array}{l}-0.007 \\
(0.164)\end{array}$ \\
\hline$f_{t \mid t-1}$ & $\begin{array}{c}0.512^{\mathrm{a}} \\
(0.142)\end{array}$ & $\begin{array}{c}0.533^{\mathrm{a}} \\
(0.159)\end{array}$ & $\begin{array}{r}0.203 \\
(0.161)\end{array}$ & $\begin{array}{c}0.297^{\mathrm{a}} \\
(0.095)\end{array}$ & $\begin{array}{c}0.286^{\mathrm{a}} \\
(0.089)\end{array}$ & $\begin{array}{c}0.291^{b} \\
(0.120)\end{array}$ \\
\hline$f_{t \mid t-2}$ & $\begin{array}{r}0.230^{\mathrm{a}} \\
(0.065)\end{array}$ & $\begin{array}{r}0.116 \\
(0.107)\end{array}$ & $\begin{array}{l}0.253^{b} \\
(0.094)\end{array}$ & $\begin{array}{c}0.196^{\mathrm{b}} \\
(0.072)\end{array}$ & $\begin{array}{r}0.255^{\mathrm{a}} \\
(0.084)\end{array}$ & $\begin{array}{r}0.265^{\mathrm{a}} \\
(0.060)\end{array}$ \\
\hline$f_{t \mid t-3}$ & $\begin{array}{l}-0.009 \\
(0.090)\end{array}$ & $\begin{array}{l}-0.003 \\
(0.092)\end{array}$ & $\begin{array}{r}0.068 \\
(0.097)\end{array}$ & $\begin{array}{c}0.108^{c} \\
(0.061)\end{array}$ & $\begin{array}{c}0.137^{\mathrm{c}} \\
(0.070)\end{array}$ & $\begin{array}{c}0.124^{b} \\
(0.052)\end{array}$ \\
\hline$f_{t \mid t-4}$ & $\begin{array}{l}-0.033 \\
(0.049)\end{array}$ & $\begin{array}{r}0.017 \\
(0.042)\end{array}$ & $\begin{array}{r}0.032 \\
(0.036)\end{array}$ & $\begin{array}{r}0.073 \\
(0.056)\end{array}$ & $\begin{array}{l}0.100^{c} \\
(0.052)\end{array}$ & $\begin{array}{r}0.083 \\
(0.057)\end{array}$ \\
\hline$g_{t}$ & $\begin{array}{r}-0.074^{\mathrm{a}} \\
(0.025)\end{array}$ & $\begin{array}{r}-0.064^{b} \\
(0.026)\end{array}$ & $\begin{array}{l}-0.028 \\
(0.020)\end{array}$ & $\begin{array}{l}-0.022 \\
(0.023)\end{array}$ & $\begin{array}{l}-0.580 \\
(0.467)\end{array}$ & $\begin{array}{r}-0.164^{\mathrm{a}} \\
(0.026)\end{array}$ \\
\hline$g_{t-1}$ & & & $\begin{array}{r}-0.094^{\mathrm{a}} \\
(0.032)\end{array}$ & & & \\
\hline$b_{t-1}$ & $\begin{array}{r}0.013 \\
(0.009)\end{array}$ & $\begin{array}{r}0.016 \\
(0.009)\end{array}$ & $\begin{array}{l}0.015^{\mathrm{b}} \\
(0.007)\end{array}$ & $\begin{array}{r}0.040^{c} \\
(0.023)\end{array}$ & $\begin{array}{c}0.721^{\mathrm{a}} \\
(0.188)\end{array}$ & $\begin{array}{r}0.035 \\
(0.026)\end{array}$ \\
\hline$\alpha$ & $\begin{array}{l}-0.121 \\
(0.164)\end{array}$ & $\begin{array}{l}-0.159 \\
(0.169)\end{array}$ & $\begin{array}{l}-0.111 \\
(0.117)\end{array}$ & $\begin{array}{l}-0.465 \\
(0.432)\end{array}$ & $\begin{array}{r}-6.558^{b} \\
(3.082)\end{array}$ & $\begin{array}{l}-0.353 \\
(0.457)\end{array}$ \\
\hline$\rho_{1}$ & & & & $\begin{array}{c}1.087^{\mathrm{a}} \\
(0.123)\end{array}$ & $\begin{array}{c}0.813^{b} \\
(0.306)\end{array}$ & $\begin{array}{r}1.143^{\mathrm{a}} \\
(0.201)\end{array}$ \\
\hline$\rho_{2}$ & & & & $\begin{array}{r}-0.476^{\mathrm{a}} \\
(0.121)\end{array}$ & $\begin{array}{r}-0.425^{c} \\
(0.210)\end{array}$ & $\begin{array}{r}-0.494^{b} \\
(0.231)\end{array}$ \\
\hline$p_{t-2}$ & $\begin{array}{c}0.472^{\mathrm{a}} \\
(0.072)\end{array}$ & $\begin{array}{c}0.651^{\mathrm{a}} \\
(0.145) \\
-0.218 \\
(0.139)\end{array}$ & $\begin{array}{c}0.540^{\mathrm{a}} \\
(0.159) \\
-0.181 \\
(0.125)\end{array}$ & & & \\
\hline Obs. & 42 & 42 & 42 & 42 & 42 & 42 \\
\hline Adj. $R^{2}$ & 0.840 & 0.851 & 0.881 & 0.830 & 0.905 & 0.889 \\
\hline AIC & -0.213 & -0.267 & -0.481 & -0.186 & & \\
\hline SIC & 0.283 & 0.271 & 0.099 & 0.278 & & \\
\hline
\end{tabular}

Dependent variable: Primary balance-GDP ratio. Robust standard errors are given in parentheses. See Eqs. (1) and (2), and main text for further details. ${ }^{a} /{ }^{b}{ }^{c}$ indicates statistical significance at the $1 \% / 5 \% / 10 \%$ level. AIC: Akaike information criterion. SIC: Schwarz information criterion.

a significant impact of the three-years ahead forecast errors while the impact of the one-year ahead error is more sizeable. If we add two lags of the dependent variable (A8), the coefficient for the two-years ahead forecast error becomes smaller and statistically insignificant. This might be due to the correlation pattern among 
forecast errors and the correlation with the budget balance. Adding the lagged output gap as additional explanatory variable (A9) restores again the significance of the two-years ahead forecast error, which could be an indication that specification A8 may be suffering from an omitted variable bias. Moreover, comparing the AIC and SIC information criteria across the different specifications, we find that both favor a specification with AR errors instead of a specification with a lagged dependent variable. Next, we check the impact of the set of dummy variables. To this end, we estimate a specification that only includes a dummy for the year 1992 and omits the dummy variables for 1993 and 1994 (A10). It turns out that this leaves our baseline results almost unchanged. Furthermore, we express the primary balance and the forecast errors in billion Euros instead of in relation to nominal GDP (A11). The motivation for doing so is that there could be a potential bias if the dependent variable and the independent variables are divided by a common denominator and if a constant term is included (see Kronmal 1993). We find, however, that the results regarding the forecast errors are more or less identical to those of the baseline specification. This finding is consistent with the fact that the constant term turns out insignificant when expressing the variables in relation to nominal GDP. Finally, we conduct a cyclical adjustment of the primary balance based on the output gap estimates of the European Commission and the budget sensitivity for the 'Länder' of 0.134 (i.e. the new dependent variable is $c a p_{t}=p_{t}-0.134 g_{t}$ ). If the baseline results were predominantly driven by business cycle effects, the new coefficients should drop strongly. We find that this is not the case (A12).

\section{A.2 Expenditures As Dependent Variable}

In this appendix, we present some additional results when regressing actual expenditures $e_{t}$ (excluding interest payments and expressed in relation to nominal GDP) on tax revenue forecasts and forecast errors (Table A2). ${ }^{17}$

Specification C1 shows an economically and statistically significant impact of the cross-horizon mean revenue forecast $r_{t \mid t-i}^{04}=\frac{1}{5} \sum_{i=0}^{4} r_{t \mid t-i}$ on expenditures. This is what one would expect given the previous results of specification B1. Specification C2 shows that the impact of the mean forecast error $f_{t \mid t-i}^{04}$ on expenditures is very small and not statistically distinguishable from zero. As discussed before, this suggests that revisions in revenue forecasts lead only to a minor degree to adjustments in the government's expenditure plans. Specification C3 resembles the specification in Chatagny and Soguel (2012) and shows that

17 For the specifications with expenditures as dependent variable we choose the errors to follow an $\operatorname{AR}(1)$ process. The results are very similar when assuming AR(2) errors. 
Table A2: Expenditures as dependent variable.

\begin{tabular}{|c|c|c|c|c|}
\hline & (C1) & (C2) & (C3) & (C4) \\
\hline & $e_{t}$ & $e_{t}$ & $e_{t}$ & $\boldsymbol{e}_{\boldsymbol{t}}$ \\
\hline & $1976-2017$ & 1976-2017 & $1976-2017$ & 1976-2017 \\
\hline \multirow{2}{*}{$\overline{r_{t \mid t-i}^{04}}$} & $0.554^{c}$ & 0.542 & & $0.561^{c}$ \\
\hline & $(0.301)$ & $(0.441)$ & & $(0.295)$ \\
\hline \multirow[t]{2}{*}{$f_{t \mid t-i}^{04}$} & & -0.019 & $-0.561^{c}$ & \\
\hline & & $(0.255)$ & $(0.295)$ & \\
\hline \multirow[t]{2}{*}{$r_{t}$} & & & 0.542 & -0.019 \\
\hline & & & $(0.441)$ & $(0.255)$ \\
\hline \multirow[t]{2}{*}{$g_{t}$} & -0.046 & -0.045 & -0.045 & -0.045 \\
\hline & (0.039) & $(0.036)$ & $(0.036)$ & $(0.036)$ \\
\hline \multirow[t]{2}{*}{$b_{t-1}$} & -0.044 & -0.046 & -0.046 & -0.046 \\
\hline & $(0.121)$ & $(0.160)$ & $(0.160)$ & $(0.160)$ \\
\hline \multirow[t]{2}{*}{$\alpha$} & $8.160^{c}$ & 8.296 & 8.296 & 8.296 \\
\hline & (4.304) & (6.158) & $(6.158)$ & (6.158) \\
\hline \multirow[t]{2}{*}{$\rho_{1}$} & $0.873^{\mathrm{a}}$ & $0.878^{\mathrm{a}}$ & $0.878^{\mathrm{a}}$ & $0.878^{\mathrm{a}}$ \\
\hline & $(0.187)$ & $(0.258)$ & $(0.258)$ & $(0.258)$ \\
\hline Obs. & 42 & 42 & 42 & 42 \\
\hline Adj. $R^{2}$ & 0.880 & 0.876 & 0.876 & 0.876 \\
\hline
\end{tabular}

Dependent variable: Expenditure-GDP ratio. Robust standard errors are given in parentheses. ${ }^{\mathrm{a}} /{ }^{\mathrm{b}} / \mathrm{c}$ indicates statistical significance at the $1 \% / 5 \% / 10 \%$ level.

revenue forecast errors $f_{t \mid t-i}^{04}$ affect expenditures in a similar magnitude as actual revenues $r_{t}$. Finally, specification $\mathrm{C} 4$ shows that expenditures significantly react to the mean revenue forecast $r_{t \mid t-i}^{04}$ but not to actual revenues $r_{t}$. It is important to note that specification $\mathrm{C} 3$ and $\mathrm{C} 4$ are just reformulations of specification $\mathrm{C} 2$. Thus, all coefficient estimates of specification C3 or C4, respectively, can also be directly calculated from the previous regression results and vice versa.

\section{A.3 Data Sources}

We retrieve the forecasts for the entirety of German states ('Länder') in billion Euros from press releases of the German Federal Ministry of Finance that were published after each AKS meeting. Press releases up to the year 1990 consider West Germany only. Press releases from 1991 onwards include forecasts for all 16 states of reunified Germany and in the first years after the reunification they also include separate forecasts for the 11 West German states and the five East German states. The year 1995 is the first year for which forecasts for all 16 states of reunified 
Germany are available at all forecast horizons. As described in the main text, we therefore consider the forecast errors for the entirety of the 11 West German states until 1994 and the forecast errors for the entirety of all 16 states of reunified Germany from 1995 onwards.

We use final nominal GDP of West Germany for all years up to 1991 and of reunified Germany for the years thereafter. These data are taken from the Federal Statistical Office, Fachserie 18, Reihe S.29 (release date September 2006) and Fachserie 18, Reihe 1.4 (release date August 2018). From the same sources we also take the budget balances, expenditures and interest payments of the entirety of German states. Data on the indebtedness of the entirety of German states are taken from the Federal Statistical Office, Fachserie 14, Reihe 5 (release date August 2018). Finally, the Hodrick-Prescott filter-based and production function-based output gap series for Germany are taken from the European Commission's AMECO database.

\section{References}

Auerbach, A.J. (2006). Budget windows, sunsets, and fiscal control. J. Publ. Econ. 90: 87-100. Beaudry, P. and Willems, T. (2018). On the macroeconomic consequences of over-optimism. National Bureau of Economic Research, NBER Working Paper 24685.

Beetsma, R., Giuliodori, M., Walschot, M., and Wierts, P. (2013). Fifty years of fiscal planning and implementation in The Netherlands. Eur. J. Polit. Econ. 31: 119-138.

Beetsma, R., Giuliodori, M., and Wierts, P. (2009). Planning to cheat: EU fiscal policy in real time. Econ. Pol. 24: 753-804.

Bischoff, I. and Gohout, W. (2010). The political economy of tax projections. Int. Tax Publ. Finance 17: 133-150.

Breuer, C. (2015). On the rationality of medium-term tax revenue forecasts: evidence from Germany. J. Econ. Stat. 235: 22-40.

Büttner, T. and Kauder, B. (2010). Revenue forecasting practices: differences across countries and consequences for forecasting performance. Fisc. Stud. 31: 313-340.

Büttner, T. and Kauder, B. (2015). Political biases despite external expert participation? An empirical analysis of tax revenue forecasts in Germany. Publ. Choice 164: 287-307.

Chatagny, F. and Soguel, N. (2012). The effect of tax revenue budgeting errors on fiscal balance: evidence from the Swiss cantons. Int. Tax Publ. Finance 19: 319-337.

Cimadomo, J. (2012). Fiscal policy in real time. Scand. J. Econ. 114: 440-465.

Cimadomo, J. (2016). Real-time data and fiscal policy analysis: a survey of the literature. J. Econ. Surv. 30: 302-326.

European Commission (2018). Report on public finances in EMU, European Economy Institutional Paper 095.

Federal Ministry of Finance (2019). Working party on tax revenue estimates, Via internet. https:// www.bundesfinanzministerium.de/Content/EN/Standardartikel/Topics/Taxation/Articles/ working-party-on-tax-revenue-estimates.html (February 2019). 
Golinelli, R. and Momigliano, S. (2009). The cyclical reaction of fiscal policies in the euro area: the role of modelling choices and data vintages. Fisc. Stud. 30: 39-72.

Hayo, B. and Neumeier, F. (2014). Political leaders' socioeconomic background and fiscal performance in Germany. Eur. J. Polit. Econ. 34: 184-205.

Heinemann, F. (2006). Planning or propaganda? An evaluation of Germany's medium-term budgetary planning. Public Finance Anal 62: 551-578.

IEO (2014). IMF forecasts: process, quality, and country perspectives. Evaluation report. Independent Evaluation Office (IEO) of the International Monetary Fund, Washington DC.

Jochimsen, B. and Lehmann, R. (2017). On the political economy of national tax revenue forecasts: evidence from OECD countries. Publ. Choice 170: 211-230.

Jochimsen, B. and Nuscheler, R. (2012). The political economy of the German Länder deficits: weak governments meet strong finance ministers. Appl. Econ. 43: 2399-2415.

Kronmal, R.A. (1993). Spurious correlation and the fallacy of the ratio standard revisited. J. Roy. Stat. Soc. 156: 379-392.

Leal, T., Pérez, J.J., Tujula, M., and Vidal, J.-P. (2008). Fiscal forecasting: lessons from the literature and challenges. Fisc. Stud. 29: 347-386.

Lehmann, R. and Wollmershäuser, T. (2020). The macroeconomic projections of the German government: a comparison to an independent forecasting institution. Ger. Econ. Rev. 21: 235-270.

OECD (2014). New tax and expenditure elasticity estimates for EU budget surveillance. OECD Economics Department, Working Paper 1174.

Pina, A.M. and Venes, N.M. (2011). The political economy of EDP fiscal forecasts: an empirical assessment. Eur. J. Polit. Econ. 27: 534-546.

Plödt, M. and Reicher, C.A. (2015). Estimating fiscal policy reaction functions: the role of model specification. J. Macroecon. 46: 113-128.

Vlaicu, R., Verhoeven, M., Grigoli, F., and Mills, Z. (2014). Multiyear budgets and fiscal performance: panel data evidence. J. Publ. Econ. 111: 79-95. 